\title{
Blockchain para a proteção intelectual em ecossistemas de startups
}

\author{
Priscila Machado Borges Sena ${ }^{1}$, Elizabete Cristina de Souza de Aguiar Monteiro ${ }^{2}$, Ursula \\ Blattmann $^{3}$, Ricardo César Gonçalves Sant' Ana ${ }^{4}$
}

${ }^{1}$ ORCID: 0000-0002-5612-4315. Universidade Federal de Santa Catarina, Florianópolis, Santa

Catarina. priscilasena.ufsc@gmail.com.

${ }^{2}$ ORCID: 0000-0002-3797-8139. Universidade Estadual Paulista, Marília, São Paulo.

ecsamonteiro@gmail.com.

${ }^{3}$ ORCID: 0000-0002-8834-0987. Programa de Pós-Graduação em Ciência da Informação da

Universidade Federal de Santa Catarina, Florianópolis, Santa Catarina. ursula.blattmann@ufsc.br.

${ }^{4}$ ORCID: 0000-0003-1387-4519. Universidade Estadual Paulista, Marília, São Paulo.

ricardo.santana@unesp.br

\section{Tipo de contribuição: Pôster}

Palavras-chave: Blockchain; Ecossistemas de Startups; Propriedade Intelectual; Direito Autoral; Propriedade industrial.

As startups são constituídas de forma espontânea no risco e na incerteza, assim possuem em sua essência a inovação com vistas a criar produtos e serviços revolucionários para o mercado (Ries, 2012). Os aglomerados denominados como ecossistemas podem ser considerados como comunidades de organizações e indivíduos (empreendedores, investidores, incubadoras) e outros grupos de interesse, unidos para realizarem atividades econômicas e sociais (Sena, Amorim \& Blattmann, 2019, no prelo). Pressupõe-se a criatividade como capacidade motriz dos ecossistemas de startups e deste modo traz luz a problemática de como manter a dinâmica inovativa dos ecossistemas de startups e garantir a proteção intelectual das ideias. O registro de inovações pode ocorrer por meio de patentes, que no Brasil geralmente ocorre com o produto final. Em relação à startups é viável registrar as ideias antes da finalização. Uma alternativa que pode ser aplicada para os aspectos de proveniência e proteção intelectual das ideias é a tecnologia blockchain, um registro público, descentralizado com base em uma arquitetura uniformemente distribuída, à prova de adulteração, que registra todas as transações que são executadas no sistema em um momento específico, com data e hora, tendo a possibilidade de rastrear a proveniência dos dados (Kim \&Laskowski, 2018; Monteiro et al, 2019). Posto isso, objetiva-se investigar a aplicação do blockchain para proteção intelectual em ecossistemas de startups, bem como indicar as vantagens e desafios da sua adoção. Caracteriza-se este trabalho como uma pesquisa exploratória descritiva, a partir do estudo bibliométrico dos dados recuperados em bases internacionais. Os termos utilizados foram "blockchain AND startup", sem delimitação de período nas bases de dados Scopus e Web of Science (WoS), em 07 de janeiro de 2019. Como resultado obteve-se 21 documentos. Em relação ao número de publicações por ano, 2019 apresenta duas, 2018 três, 2017 duas, e 2016 uma, demonstrando que a temática é recente na literatura científica. Quanto às autorias e os títulos dos periódicos, verifica-se que não se repetem em um nenhum dos artigos. Já em relação ao foco e escopo dos artigos e dos periódicos, nota-se que as áreas de Tecnologia da Informação e Economia são mais presentes. Os artigos analisados apresentaram exemplos de startups que estão desenvolvendo negócios baseados na tecnologia blockchain, inclusive com o uso de criptomoedas, de aplicativos e modelos de negócios que estão transformando a maneira como as startups fazem transações comerciais, gerenciam ativos digitais e capturam recursos financeiros. Sobre as 
vantagens da adoção do blockchain em Ecossistemas de Startups, verifica-se que circundam em torno da agilidade de registro de uma autoria e do acompanhamento das alterações posteriores, mantendo a dinâmica inovativa dos ecossistemas de startups e garantindo a proteção intelectual. Como desafios vislumbra-se oportunidades de estudos em diversas áreas do conhecimento, o que faz do profissional da informação um agente de destaque na mediação dos fatores envolvidos, uma vez que em sua área de pesquisa e atuação estão relacionados com aspectos ligados à dinâmica apresentada. Como futuras pesquisas almeja-se a investigação da temática em revistas profissionais, especializadas em economia e direito, e no campo empírico de modo geral, no sentido de relacionar e desenvolver os aspectos citados como vantagens e desafios.

\section{Agradecimentos}

À Coordenação de Aperfeiçoamento de Pessoal de Nível Superior (CAPES) do Brasil por financiar a bolsa de estudos do doutorado em andamento.

\section{Referências}

Kim, H. M., \& Laskowski, M. (2018). Toward an ontology-driven blockchain design for supply-chain provenance. Intelligent Systems in Accounting, Finance and Management, 25(1), 1827. Recuperado em 7 janeiro, 2019, de https://onlinelibrary.wiley.com/doi/full/10.1002/isaf.1424

Monteiro, E. C. S. A. et al. (no prelo). Proteção autoral de dados: uso de blockchain. In: $2^{\circ}$ Workshop de Informação, Dados e Tecnologia (WIDaT). João Pessoa: Editora universitária.

Ries, E.(2012). A startup enxuta. São Paulo: Leya.

Scopus. Recuperado em 7 janeiro, 2019, de https://www-scopuscom.ez46.periodicos.capes.gov.br/search/form.uri?display=basic

Sena, P.M.B., Amorim, I. S., \& Blattmann, U. (no prelo). Informação para autonomia em negócios, inovação e tecnologia. Brajis - Brazilian Journal of Information Science: Research Trends.

Web of science (WoS). Recuperado em 7 janeiro, 2019, de https://webofknowledge.com 